\title{
Is Resection a Panacea for managing Furcation Predicament? A Report of Two Cases
}

\author{
${ }^{1}$ Yashashri Sunil Chaudhari, ${ }^{2}$ Vishwas Madaan, ${ }^{3}$ Himani Gupta, ${ }^{4}$ Ashvini M Padhye
}

\begin{abstract}
The presence of attachment loss in the furcation is one of the most serious anatomical sequels of periodontitis. Furcations are not accessible for professional debridement, as their entrance is small compared with the size of periodontal instruments, and they present with ridges, convexities, and concavities that make it difficult for clinicians to debride effectively. Advances in dentistry have provided the opportunity for clinicians to provide patients with the option of retaining their teeth in the long-term. Such teeth can be useful as independent units of mastication or as abutments in simple fixed bridges. This article presents two cases of advanced furcation defects, which were treated by two different resective periodontal therapeutic modalities.
\end{abstract}

Keywords: Furcation, Resective, Tunneling.

How to cite this article: Chaudhari YS, Madaan V, Gupta H, Padhye AM. Is Resection a Panacea for managing Furcation Predicament? A Report of Two Cases. J Contemp Dent 2016; 6(1):38-44.

\section{Source of support: Nil}

Conflict of interest: None

\section{BACKGROUND}

Furcation involvement is defined as bone resorption and attachment loss in the interradicular space that results from plaque-associated periodontal disease. ${ }^{1}$ The management and long-term retention of molar teeth with furcation involvement has been a challenge for clinicians since time immemorial. Owing to the complex anatomy of multirooted molar teeth characterized by ridges, concavities, bifurcation ledges, cervical enamel projections, and other developmental anomalies present in the furcation region, ${ }^{2}$ accessibility to the furcation area is impeded for professional root debridement. ${ }^{3}$ The arduous nature of furcation sites spells doom for molar teeth, as they respond less favorably to conventional periodontal treatment than their respective flat surfaces.

${ }^{1,2}$ Postgraduate Student, ${ }^{3}$ Senior Lecturer, ${ }^{4}$ Guide, Professor and Head

${ }^{1-4}$ Department of Periodontology, MGM Dental College and Hospital, Navi Mumbai, Maharashtra, India

Corresponding Author: Yashashri Sunil Chaudhari, B-3/34 Bachani Nagar, Daftary Road, Malad (East), Mumbai 400097, Maharashtra, India, Phone: +09820988518, e-mail: yashashri1806@gmail.com
In spite of this, the decision to retain and treat teeth with furcation involvement has been recognized as a feasible and predictable modality when appropriate treatment parameters are addressed. ${ }^{4-6}$ Survival rates of teeth affected with furcation defects, after regenerative and resective therapy, have ranged from 83 to $100 \%$, as observed over a period of 5 years. ${ }^{7}$

Glickman has classified furcation involvement into four grades as follows: Grade I - incipient involvement with suprabony pocket and no radiographic evidence of bone loss, grade II - cul-de-sac involvement, grade III - through and through furcation involvement with soft tissue covering the furcation entrance, and grade IV - through and through furcation involvement with exposed furcation entrance. Among the following, grade III and IV involved furcation are considered to have poor to hopeless prognosis, as instating plaque control measures to clean these inaccessible areas is impossible and extraction of such teeth in near future becomes mandatory. With the introduction of resective therapies for treating advanced furcation defects since the past 20 years, compromised teeth can be rejuvenated and upgraded to a status of fair prognosis. ${ }^{8}$ Moreover, the long-term success rate of these surgically managed teeth $(96.7 \%$; 701 molars) is abreast with the survival rates of dental implants (97\%; 1472 implants). ${ }^{9}$ In comparison to rehabilitation with implants, effectively treating a furcation has shown to be less invasive, cost-effective, retain the proprioception of periodontal ligament, and require fewer appointments.

The treatment options available for teeth with advanced furcation involvement involve regenerative and/or resective approaches. Various resective procedures described in literature are hemisection, radisection, bicuspidization, and tunneling. Root resection is the process by which one or more of the roots of a tooth are removed at the level of the furcation, while leaving the crown and remaining roots in function. ${ }^{10}$ It can be vital root resection ${ }^{11}$ or nonvital root resection. ${ }^{12}$ Tunnel preparation is the intentional widening of the furcation entrance, making it amenable and accessible for performing oral hygiene procedures. ${ }^{13}$

This article brings to you a report of two cases of advanced furcation defects managed successfully with resective periodontal surgical procedures. 


\section{CASE REPORTS}

\section{Case 1}

A 60-year-old male patient reported to the Department of Periodontics at MGM Dental College and Hospital with a complaint of pain in his left lower posterior region since 1 month. The pain was dull and throbbing, with no associated relieving or aggravating factors. Patient had no history of systemic involvement, such as presence of diabetes mellitus, hypertension, and immunocompromised condition. Clinical examination revealed fair oral hygiene status and the presence of grade IV furcation involvement in left mandibular first permanent molar (36) as diagnosed with a Naber's probe (Fig. 1) and wear facets due to presence of traumatic occlusion. Radiographic examination revealed adequate bone present expect in the furcation region (Fig. 2). Phase I therapy comprised thorough scaling and root planing to eliminate local factors along with coronoplasty (to correct traumatic occlusion) and oral hygiene instructions were given. Vitality testing of 36 with ethyl chloride spray (cold test) and electric pulp testing revealed delayed response. Hence, endodontic treatment was carried out prior to periodontal surgical procedure. On subsequent follow-up visits, it was noted that the open furcation site of 36 was acting as a nidus for accumulation of local irritants in spite of overall good oral hygiene maintenance. Hence, the option of resective therapy was considered and a treatment plan was formulated to perform tunneling procedure so as to modify the furcation dilemma into a self-cleansable area.

Following administration of local anesthetic agent $(2 \%$ lignocaine with 1:2,00,000 adrenaline), a full-thickness mucoperiosteal flap was reflected for the mandibular left posterior sextant (Fig. 3). Thorough debridement and root planing were performed and odontoplasty in the furcation site was done using diamond abrasive strips (coated with $15 \mu \mathrm{m}$ diamond particles, 3M ESPE Dental Products, Mumbai, India) (Figs 4 and 5), the endpoint of which corresponded to an increase in space adequate enough for passage of an interdental brush
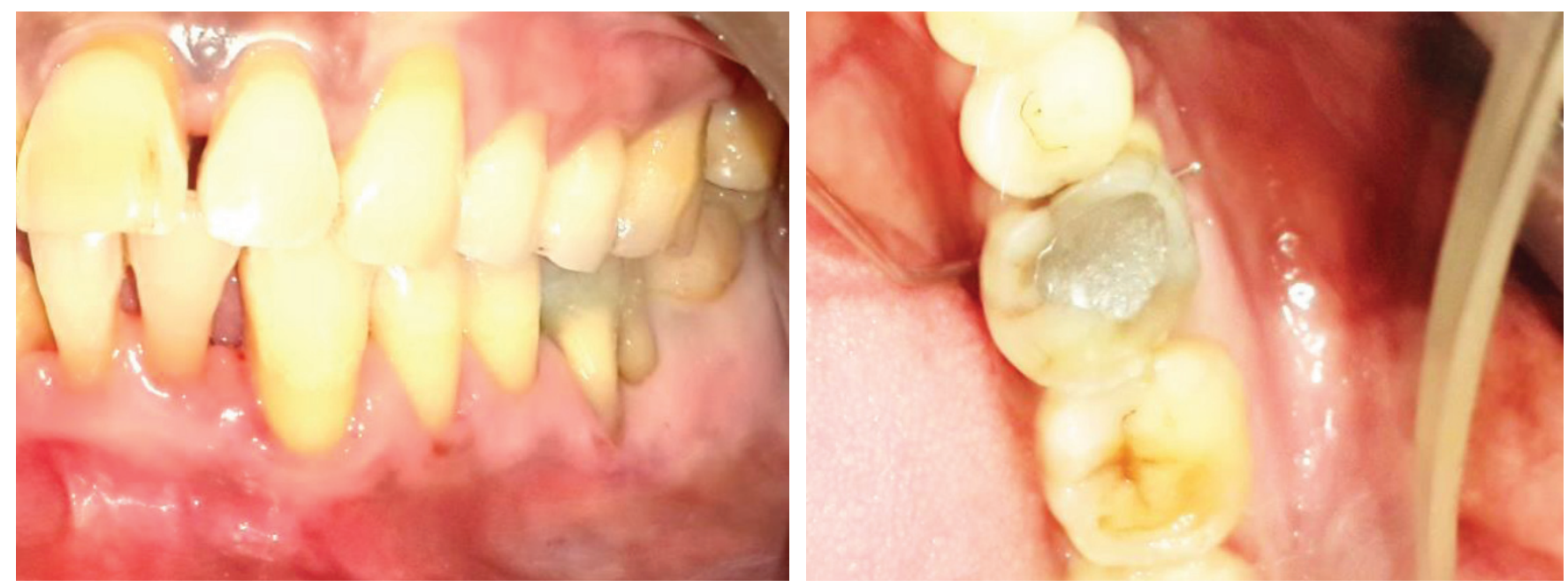

Fig. 1: Preoperative clinical view showing grade IV furcation involvement with 36

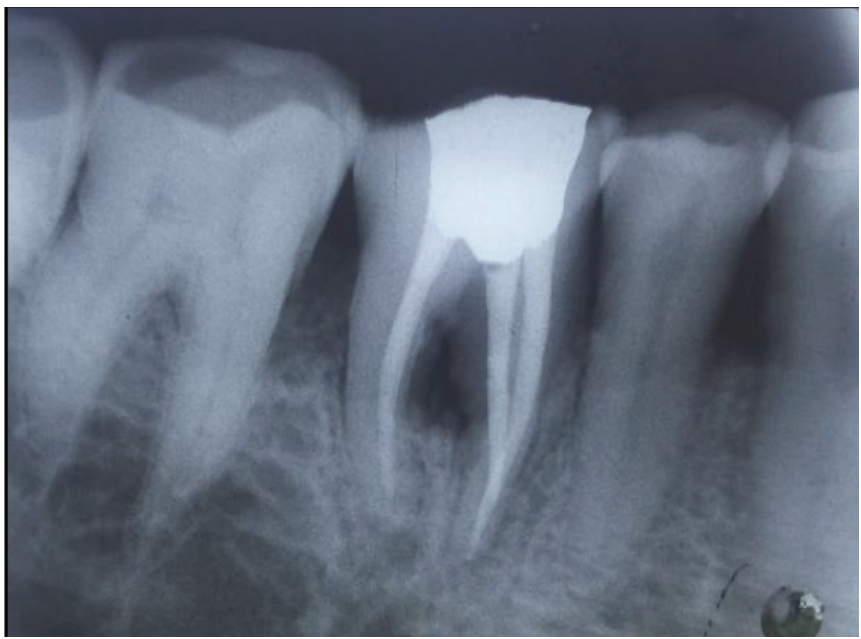

Fig. 2: Radiograph after root canal treatment with 36

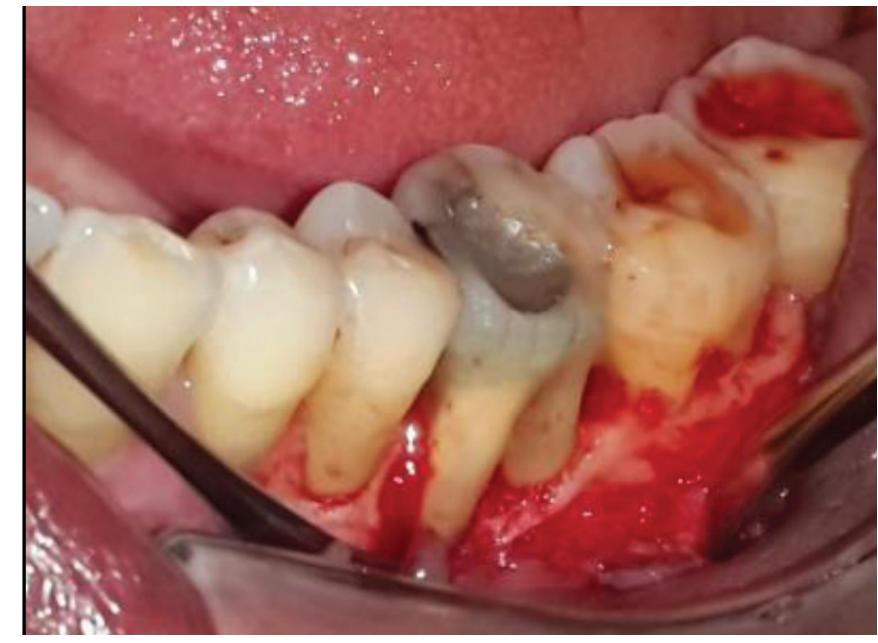

Fig. 3: Full thickness mucoperiosteal flap raised 


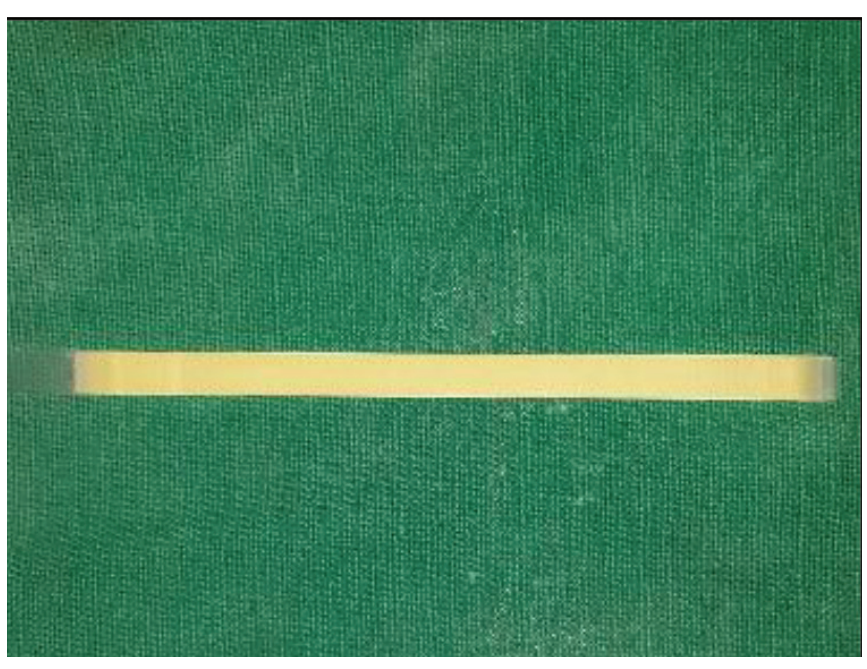

Fig. 4: Diamond abrasive strip

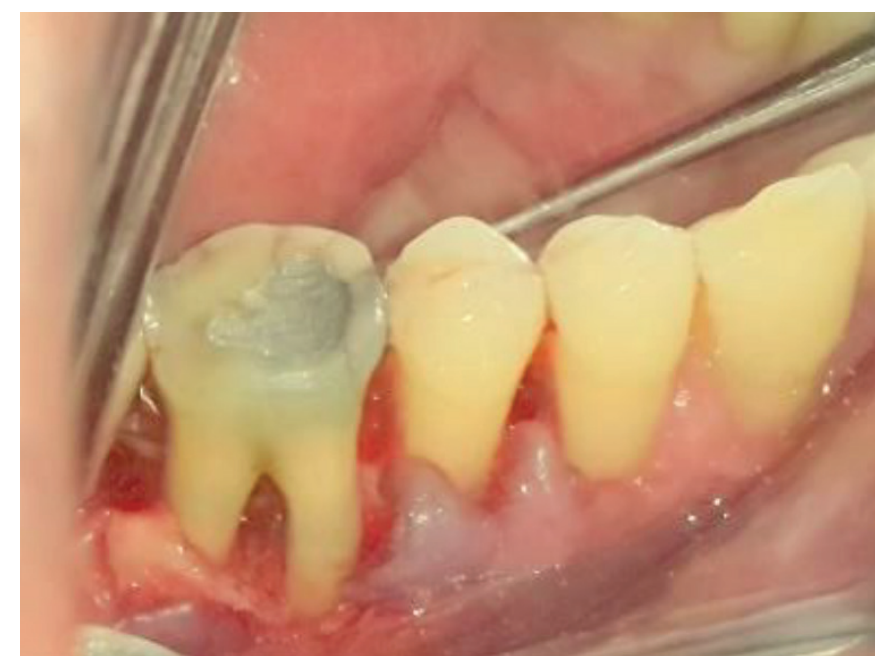

Fig. 6: Tunnel preparation completed

easily through the furcation region (Fig. 6). Sharp bony margins and ledges were recontoured to achieve a near-normal architecture. The flap was then apically repositioned and interrupted direct loop sutures were given using 3-0 black silk suture (Fig. 7). Drug regimen postoperatively was composed of antibiotic-Amoxicillin $500 \mathrm{mg}$ thrice daily with an anti-inflammatory drug with a combination of diclofenac sodium, acetaminophen, and serratiopeptidase twice daily for a period of 5 days. Patient was also instructed to rinse twice daily with $10 \mathrm{ml}$ of $0.2 \%$ chlorhexidene gluconate for 2 weeks. Suture removal was done 1 week postoperatively. On a monthly follow-up visit, the patient reported with no discomfort and healing was found to be satisfactory (Figs 8 and 9).

\section{Case 2}

A 36-year-old male patient reported to the Department of Periodontics at MGM Dental College and Hospital with difficulty in chewing food from his upper left back tooth region since past 9 months. Patient was systemically

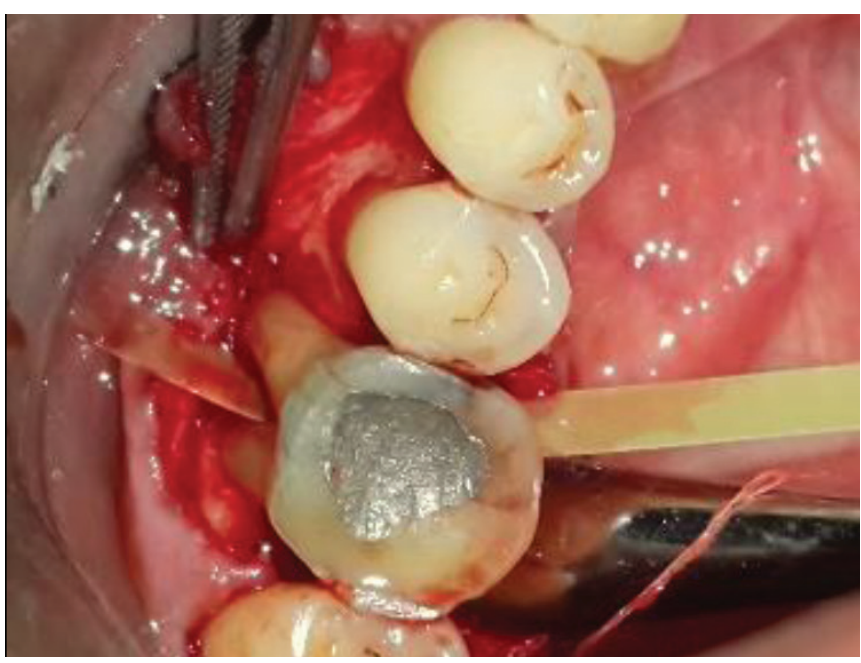

Fig. 5: Odontoplasty with diamond abrasive strip in the furcal area

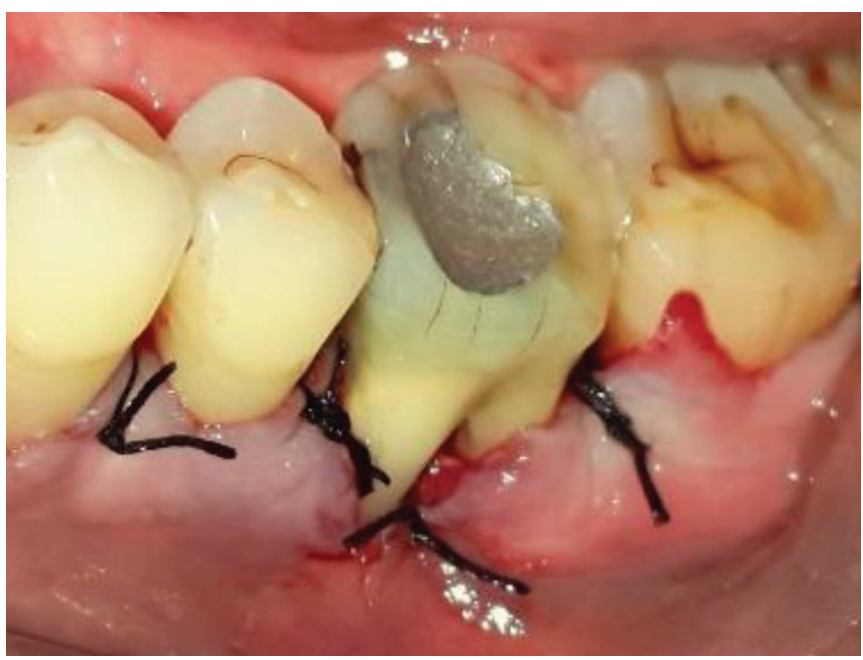

Fig. 7: Sutures placed

healthy. Intraoral examination revealed fair oral hygiene status with presence of bleeding on probing along with deep periodontal pockets present in relation to 25,26 , and 27. In the area of the chief complaint, an $8 \mathrm{~mm}$ probing pocket depth was present with the distobuccal aspect of maxillary left first permanent molar (26) along with grade I mobility (Fig. 10). Radiograph revealed interproximal bone present only in the apical third of the distal aspect of 26 (Fig. 11). The tooth was diagnosed to be nonvital, as it failed to respond to testing with ethyl chloride spray (cold test) and electric pulp testing. Hence, root canal treatment was completed prior to surgical intervention.

With respect to resective periodontal surgical procedure, the distobuccal root in maxillary molars is the preferred alternative for root resection, as it is the shortest of the three roots with oval cross section, invested in a small quantity of bone. ${ }^{13}$ Comparatively, the mesiobuccal root has a larger root surface and is centrally located with premolars, creating ideal position to function as a 

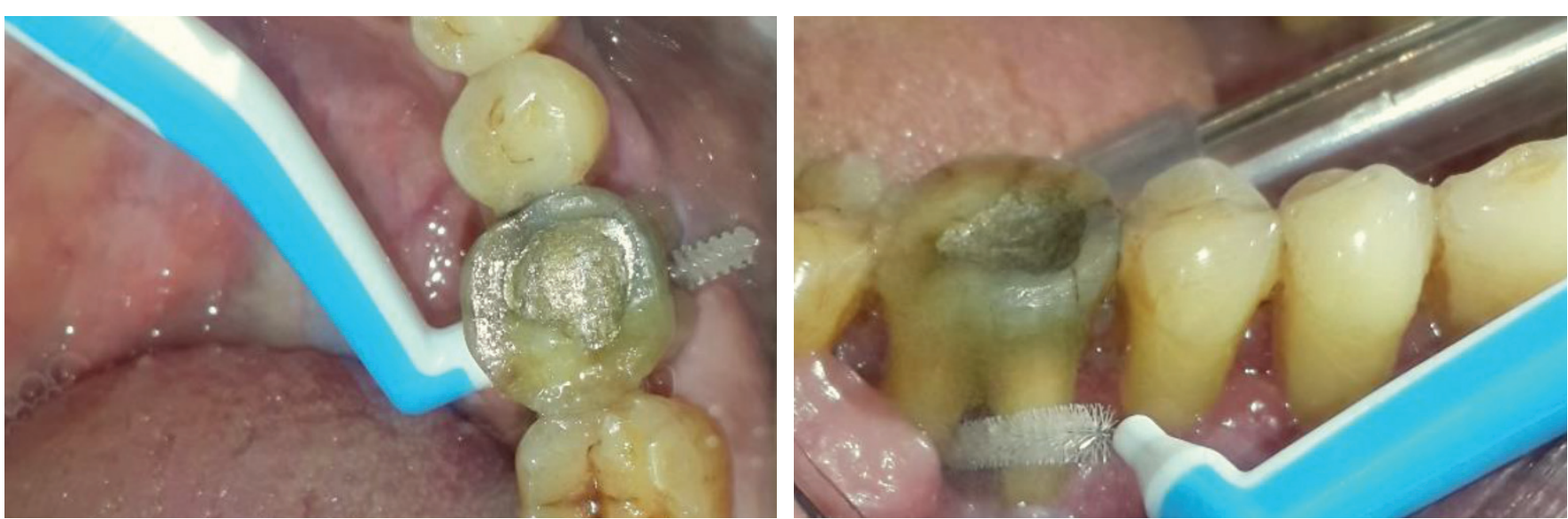

Fig. 8: One month postoperative clinical view with use of interdental brush

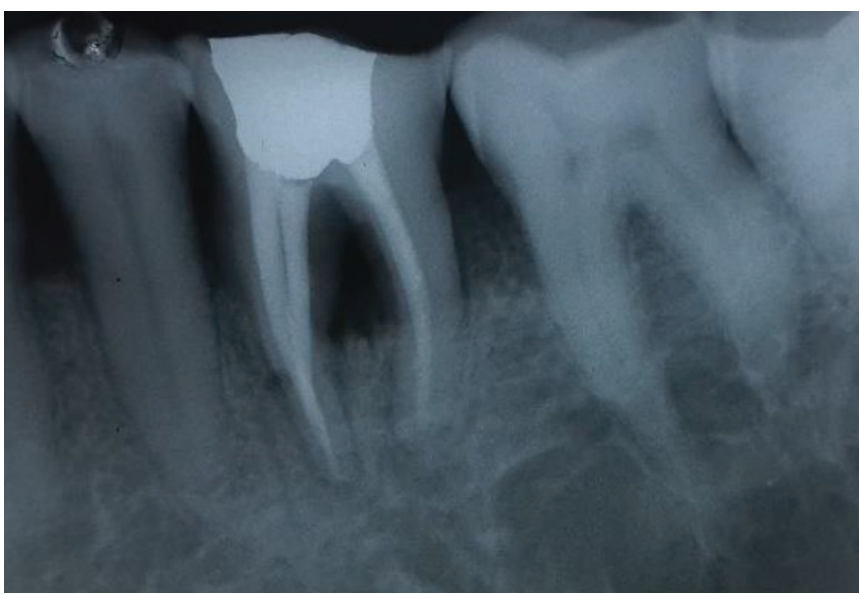

Fig. 9: One month postoperative radiograph

separate unit ${ }^{14}$. With all these points in consideration, a distobuccal root resection was planned. A full-thickness muco-periosteal flap was reflected in relation to 25,26 , and 27 (Fig. 12) after administration of local anesthetic agent ( $2 \%$ lignocaine with 1:2,00,000 adrenaline). Exposure of the surgical site revealed complete loss of bone on the distal aspect of distobuccal root of 26 along with interradicular bone loss. The cementoenamel junction

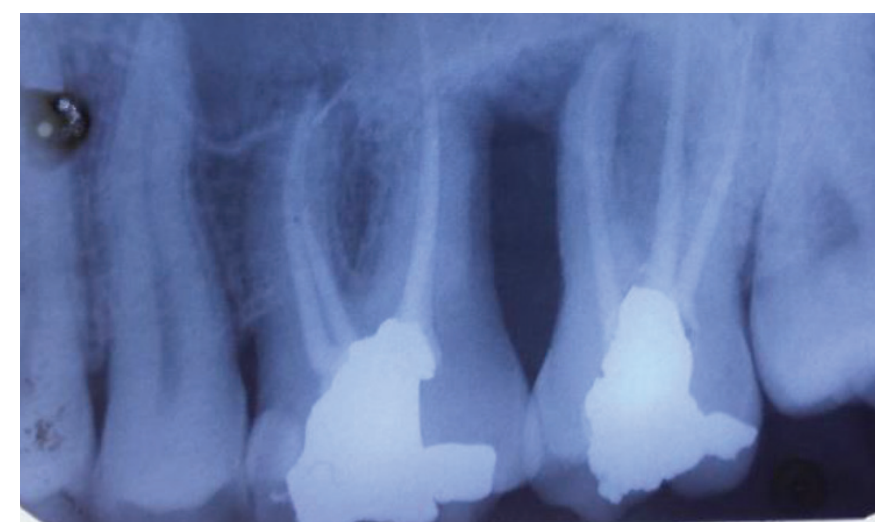

Fig. 11: Radiograph after root canal treatment of 26 and 27

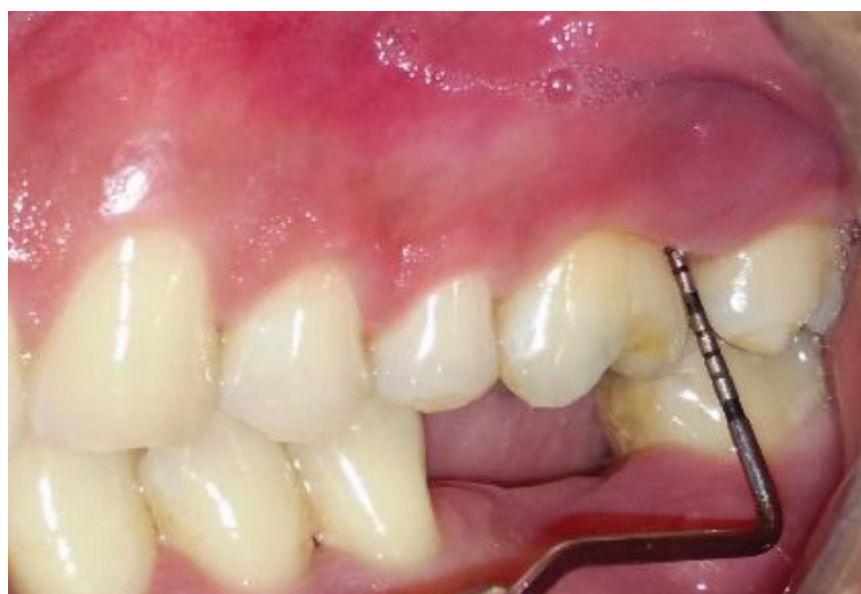

Fig. 10: Preoperative clinical view showing $8 \mathrm{~mm}$ probing depth

was identified and the confluence of the distobuccal root with the root trunk was marked with an indelible pencil that served as a guide for the initial cut to be made with a diamond coated cylindrical bur (Fig. 13). Care was taken not to damage the adjacent root structure by inserting wooden wedges in the trifurcation area. After completion of the cut, the resected root was gently luxated out with a periosteal elevator (Figs 14 and 15). The remnant

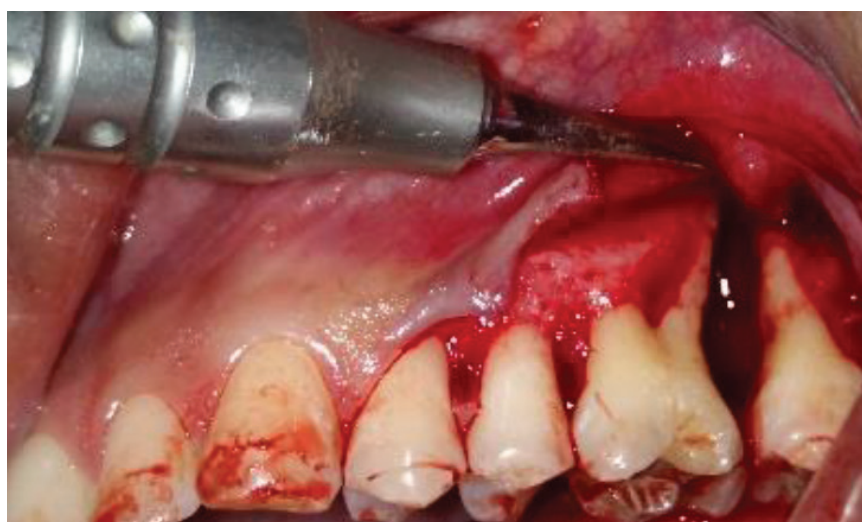

Fig. 12: Full thickness mucoperiosteal flap raised with selection of distobuccal root for resection 


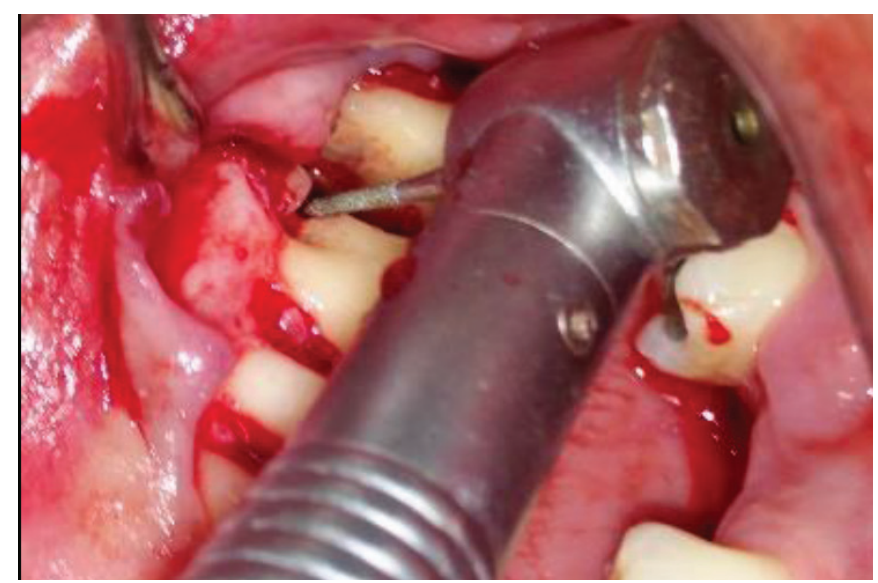

Fig. 13: Use of diamond coated bur for root resection

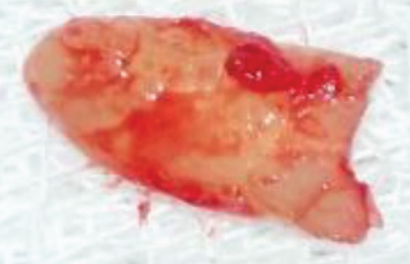

Fig. 15: Resected distobuccal root

stump of distobuccal root was sealed with glass ionomer restorative cement (GC Fuji II, Mumbai, India) (Fig. 16) for sealing off the exposed dentinal tubules. The mobility of the remaining tooth root complex was checked. Flap closure was done using interrupted direct loop suture with 3-0 black silk (Fig. 17). Drug regimen postoperatively was composed of antibiotic-Amoxicillin $500 \mathrm{mg}$ thrice daily with an anti-inflammatory drug with a

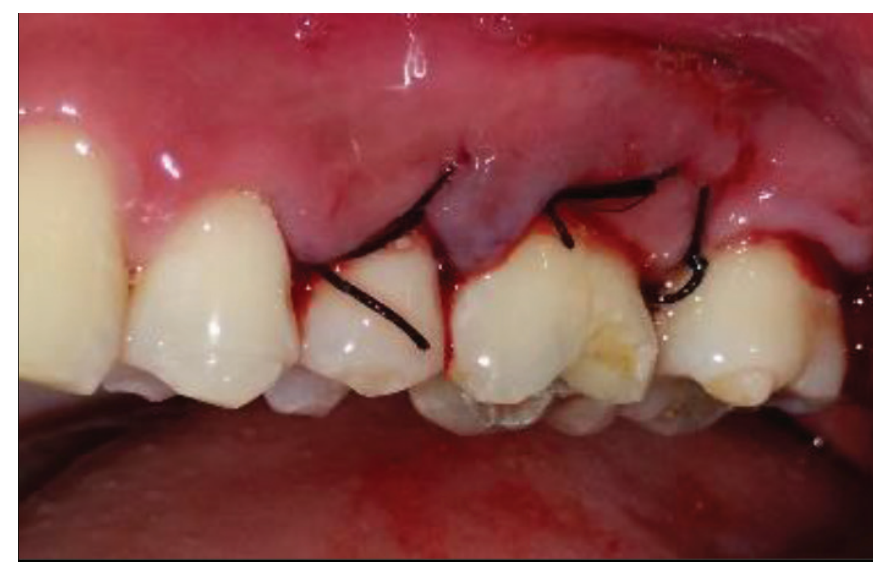

Fig. 17: Sutures placed

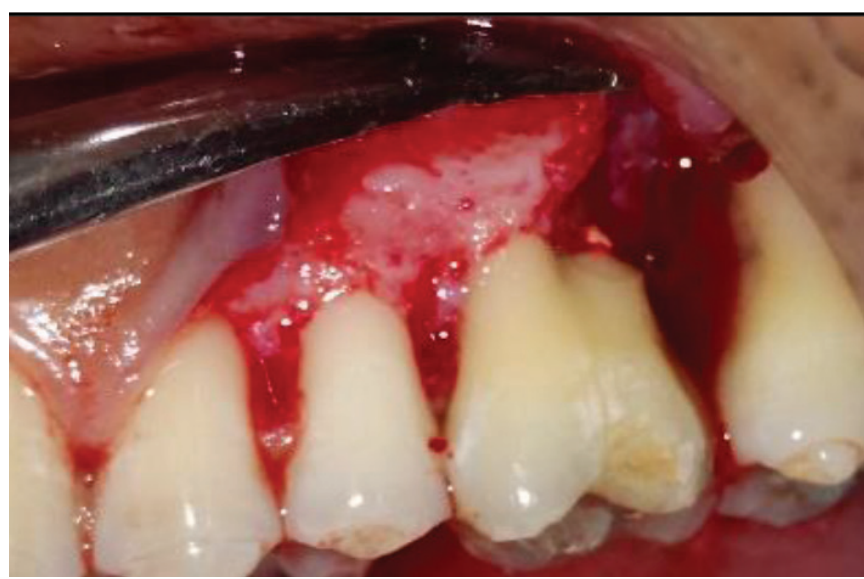

Fig. 14: Perioperative view

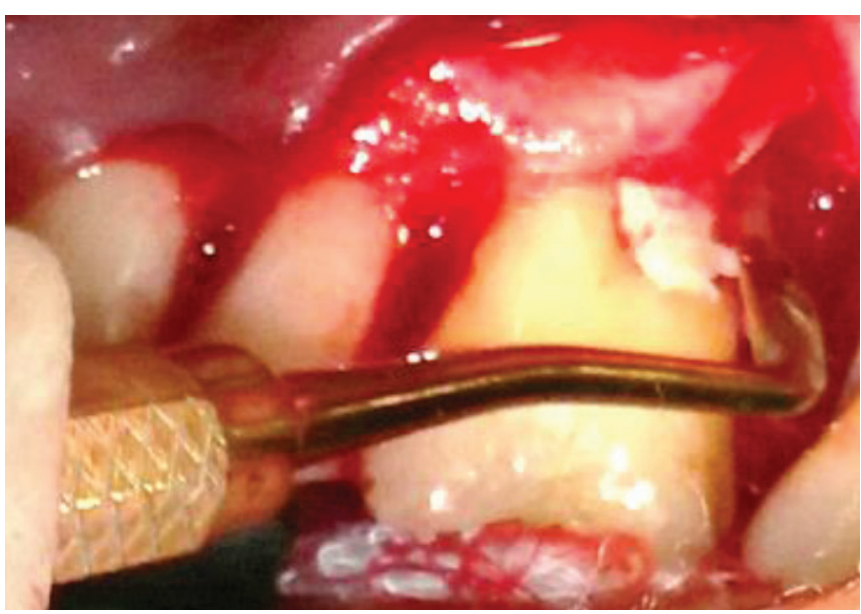

Fig. 16: Glass-ionomer cement application on stump of resected root

combination of diclofenac sodium, acetaminophen, and serratiopeptidase twice daily for a period of 5 days. Patient was also instructed to rinse twice daily with $10 \mathrm{ml}$ of $0.2 \%$ chlorhexidine gluconate for 2 weeks. Suture removal was done after 1 week. Follow-up visits were scheduled and the surgical site showed favorable healing and absence of mobility by the 6th month (Figs 18 and 19).

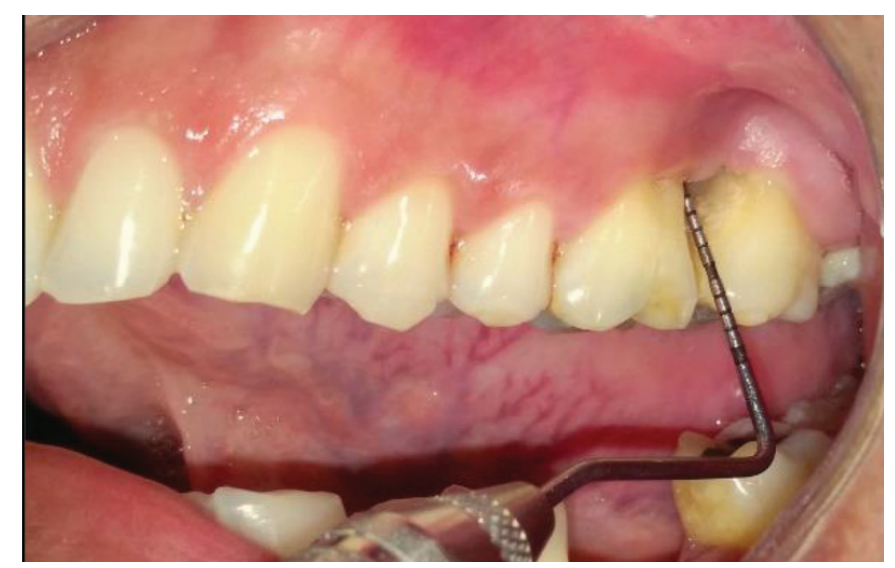

Fig. 18: Six months postoperative clinical view 


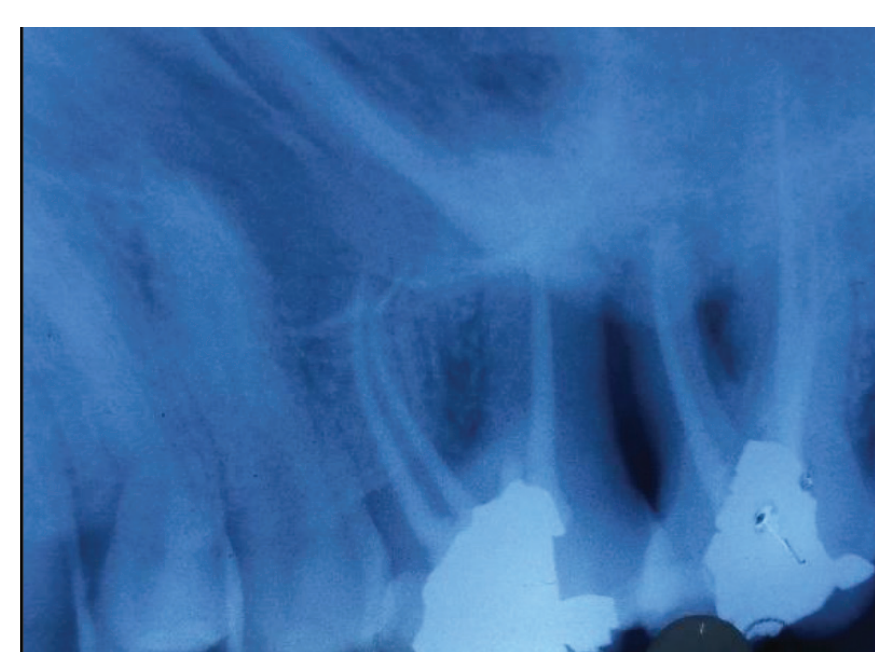

Fig. 19: Six months postoperative radiographic view

\section{DISCUSSION}

Furcation defects represent a formidable problem in the control and treatment of periodontal disease, principally related to the complicated, unpredictable, and irregular anatomy of furcation. The anatomical characteristics of the areas involved, particularly the size of the furcation entrance, the presence of root concavities, and the uneven surface of the roof of the furcation, make adequate instrumentation of the inter-radicular area extremely difficult. ${ }^{15}$ Resective therapies in these scenarios have proved to be a boon to salvage natural teeth, and thus retain the proprioception of periodontal ligament. Success of root resection procedures depends on proper case selection. Both cases presented were carefully evaluated and all treatment options were deliberated upon before deciding on the resective form of therapy. The justification of resecting tooth/root structure was aimed at making the tooth amenable to regular plaque control measures. In case 1, the interradicular distance was not wide enough preoperatively, and hence a tunneling procedure was planned that made the passage of interdental brush for oral hygiene maintenance possible. Mandibular molars, unlike their maxillary counterparts, cannot serve as successful candidates for root resection in purview that the remnant tooth root complex has less pericemental area to effectively bear the occlusal forces, thus compromising their functional surveillance in the long run. ${ }^{16}$ Hence, root resection alone is not a feasible option for birooted mandibular molars. Also, the preoperative attachment loss present on the tooth concerned ruled out any other resective form of therapy expect for the chosen one. Furthermore, there was sufficient interproximal bone present, which enabled conservative removal of bone and tooth structure in the furcal region without adversely affecting the attachment apparatus, and thereby securing a long-term prognosis for the tooth. The preparation of tunnel was confined to odotoplasty done using diamond abrasive strips that limited the compromise of sound tooth structure that could occur with rotary instruments. One commonly reported drawback associated with the tunneling procedure is the development of root caries. ${ }^{17}$ To prevent this, a fluoride-containing mouth wash was prescribed to the patient 1 month after surgery.

In case 2, the distobuccal root demonstrated maximum attachment loss and on surgical entry was found to be round. Owing to the proximity of distobuccal root of first molar to the mesiobuccal root of second molar, it was decided to resect this root to prevent further breakdown in this area. ${ }^{18}$ Also, on radiographic examination, the tooth demonstrated sufficient crown: root ratio with adequate length and width of the mesiobuccal and palatal roots that could sustain the occlusal load in the event that distobuccal root was resected.

In both the cases discussed above, the logical sequence of treatment mandated completion of endodontic treatment prior to resective periodontal surgery, as the endodontic periodontic continuum could result in exacerbation of the periodontal inflammation. In a study by Park et al ${ }_{1}^{19}$ it was concluded that molars that underwent resective procedures due to periodontal reasons had a higher success rate than those due to endodontic causes. These procedures were able to remove periodonthopathic microorganisms, calculus, unfavorable anatomic contours, hemiseptal defects, and deep intrabony defects. ${ }^{20}$ Another important factor that was given special consideration was the initial bone level present on molar roots to be salvaged. It has been shown that molars with bone support on more than $50 \%$ of the remaining roots at the time of the surgical procedure have better survival rate if the etiology was due to periodontal disease, ${ }^{20}$ as was considered during formulation of our treatment plan.

An important patient-related factor in resective periodontal procedures is the maintenance of high levels of oral hygiene by the patient. In the cases shown, the patients were able to ensure adequate plaque control. A meta-analysis by Huynh-Ba et $\mathrm{al}^{7}$ inferred that multirooted teeth with furcation involvement treated with resective surgical approach had good survival rates over a period of 10 to 15 years.

\section{CONCLUSION}

The present case reports help us to understand that resective therapies are sound treatment alternatives for teeth with advanced furcation defects, as they effectively maintain the natural teeth in function, keeping intact the proprioception of periodontal ligament. Perfect compliance of the patient with plaque control and the 
cost-benefit calculations speak in favor of this treatment. These therapies have successfully proven to be an effective treatment alternative to extraction and can provide a breath of life for teeth with ailing furcations.

\section{REFERENCES}

1. Cattabriga M, Pedrazzoli V, Wilson TG Jr. The conservative approach in the treatment of furcation lesions. Periodontol 20002000 Feb;22:133-153.

2. Bower RC. Furcation morphology relative to periodontal treatment. Furcation root surface anatomy. J Periodontol 1979 Jul;50(7):366-374.

3. Matia JI, Bissada NF, Maybury JE, Ricchetti P. Efficiency of scaling of the molar furcation area with and without surgical access. Int J Periodontics Restorative Dent 1986;6(6):24-35.

4. Jepsen S, Eberhard J, Herrera D, Needleman I. A systematic review of guided tissue regeneration for periodontal furcation defects. What is the effect of guided tissue regeneration compared with surgical debridement in the treatment of furcation defects? J Clin Periodontol 2002;29(Suppl 3):103-116.

5. Murphy KG, Gunsolley JC. Guided tissue regeneration for the treatment of periodontal intrabony and furcation defects. A systematic review. Ann Periodontol 2003 Dec;8(1):266-302.

6. Reynolds MA, Aichelmann-Reidy ME, Branch-Mays GL, Gunsolley JC. The efficacy of bone replacement grafts in the treatment of periodontal osseous defects. A systematic review. Ann Periodontol 2003 Dec;8(1):227-265.

7. Huynh-Ba G, Kuonen P, Hofer D, Schmid J, Lang NP, Salvi GE. The effect of periodontal therapy on the survival rate and incidence of complications of multirooted teeth with furcation involvement after an observation period of at least 5 years: a systematic review. J Clin Periodontol 2009 Feb;36(2):164-176.

8. Egelberg J. Periodontics-The scientific way. 3rd ed. Malmo: OdontoScience; 1998.
9. Fugazzotto PA. A comparison of the success of root resected molars and molar position implants in function in a private practice: results of up to 15-plus years. J Periodontol 2001 Aug;72(8):1113-1123.

10. American Academy of Periodontology. Glossary of Periodontal Terms. Chicago: American Academy of Periodontology; 2001. $45 \mathrm{p}$.

11. Smukler $\mathrm{H}$, tagger $\mathrm{M}$. Vital root amputation. A clinical and histologic study. J Periodontol 1976;47(6):324-330.

12. Babay NA, Almas K. A four year clinical follow up of nonvital root resection in maxillary molar teeth. Ind J Dent Res 1996 Jan-Mar;7(1):29-32.

13. Rosenberg MM. Management of osseous defects. Clin Dent 1978;3:103-105.

14. Ross IF, Thompson RH. Furcation involvement in maxillary and mandibular molars. J Periodontol 1980 Aug;51(8): 450-454.

15. DeSanctis M, Murphy KG. The role of resective periodontal surgery in the treatment of furcation defects. Periodontol 20002000 Feb;22:154-168.

16. Rosensteil SF. Contemporary fixed prosthodontic planing and preparation. St Louis: Mosby Inc.; 2001. p. 69-70.

17. Vandersall DC, Detamore RJ. The mandibular molar class III furcation invasion: a review of treatment options and a case report of tunnelling. J Am Dent Assoc 2002 Jan;133(1): 55-60.

18. Cohen E. Atlas of cosmetic and reconstructive periodontal surgery. 3rd ed. USA: BC Decker; 2007.

19. Park SY, Shin SY, Yang SM, Kye SB. Factors influencing the outcome of root-resection therapy in molars: a 10-year retrospective study. J Periodontol 2009 Jan;80(1):32-40.

20. Nieri M, Muzzi L, Cattabriga M, Rotundo R, Cairo F, Pini Prato GP. The prognostic value of several periodontal factors measured as radiographic bone level variation: a 10 -year retrospective multilevel analysis of treated and maintained periodontal patients. J Periodontol 2002 Dec;73(12):1485-1493. 